\title{
Aerosol optical characterization by nephelometer and lidar: The Baltimore Supersite experiment during the Canadian forest fire smoke intrusion
}

\author{
Mariana Adam, ${ }^{1}$ Markus Pahlow, ${ }^{1}$ Vladimir A. Kovalev, ${ }^{2}$ John M. Ondov, ${ }^{3}$ \\ Marc B. Parlange, ${ }^{1}$ and Narayanan $\mathrm{Nair}^{3}$ \\ Received 4 August 2003; revised 14 April 2004; accepted 20 May 2004; published 21 July 2004.
}

[1] High spatial and temporal resolution elastic backscatter lidar data from Baltimore are analyzed with a near-end approach to estimate vertical profiles of the aerosol extinction coefficient. The near-end approach makes use of the (1) aerosol scattering coefficient measured at the surface with a nephelometer $(0.530 \mu \mathrm{m}),(2)$ surface level particle size distribution, and (3) refractive index calculated using Mie theory to estimate the aerosol extinction coefficient boundary condition for the lidar equation. There was a broad range of atmospheric turbidity due to a strong haze event, which occurred because of smoke transport from Canadian forest fires, and led to a wide range of observed atmospheric properties. The index of refraction for aerosols estimated during the entire study period is $1.5-0.47 i$, which is typical for soot. The measured surface level aerosol scattering coefficient ranged from $\sigma_{p}=0.002$ to $\sigma_{p}=$ $0.541 \mathrm{~km}^{-1}$, and the computed aerosol extinction coefficient spanned values $\kappa_{p}=0.01$ to $\kappa_{p}=1.05 \mathrm{~km}^{-1}$. The derived mass concentration and the mass scattering ranges were $3.96-194 \mu \mathrm{g} \mathrm{m}^{-3}$ and $0.05-3.260 \mathrm{~m}^{2} \mathrm{~g}^{-1}$, respectively. The aerosol optical properties were dominated by light absorption by soot. INDEX TERMS: 0305 Atmospheric Composition and Structure: Aerosols and particles (0345, 4801); 0345 Atmospheric Composition and Structure: Pollution — urban and regional (0305); 0360 Atmospheric Composition and Structure: Transmission and scattering of radiation; 3359 Meteorology and Atmospheric Dynamics: Radiative processes; 3360 Meteorology and Atmospheric Dynamics: Remote sensing; KEYWORDS: lidar, nephelometer, extinction, scattering, mass scattering, Supersite

Citation: Adam, M., M. Pahlow, V. A. Kovalev, J. M. Ondov, M. B. Parlange, and N. Nair (2004), Aerosol optical characterization by nephelometer and lidar: The Baltimore Supersite experiment during the Canadian forest fire smoke intrusion, J. Geophys. Res., 109, D16S02, doi:10.1029/2003JD004047.

\section{Introduction}

[2] Light extinction and scattering by aerosols plays an important role in the atmospheric radiation balance [Houghton et al., 2001] and is an important factor in climatic calculations [Charlson at al., 1992; Hobbs, 1993]. Aerosols and clouds affect Earth's radiation budget by interacting with solar visible radiation and terrestrial infrared radiation. They determine what fraction of the solar radiation incident at the top of the atmosphere reaches Earth's surface and what fraction of long wave radiation from Earth escapes to space. Aerosols have unique optical

\footnotetext{
${ }^{1}$ Department of Geography and Environmental Engineering, Johns Hopkins University, Baltimore, Maryland, USA.

${ }^{2}$ Fire Science Laboratory, U.S. Department of Agriculture, Missoula, Montana, USA.

${ }^{3}$ Department of Chemistry and Biochemistry, University of Maryland, College Park, Maryland, USA.
}

Copyright 2004 by the American Geophysical Union. 0148-0227/04/2003JD004047\$09.00 properties that determine the amount of radiation they absorb or reflect into the atmosphere. These properties are important in radiative transfer calculations since they provide information about radiation losses through the atmosphere.

[3] Cities are a large source of primary soot particles owing to the high number of motor vehicles. In addition, cities tend to be dustier because cars and trucks enhance the dispersion of road dust into the air. Soot has a long residence time and affects light scattering and absorption in air and clouds for substantial distances downwind. Particle concentration and composition in cities vary widely by season and under different meteorological conditions. In this respect the optical characterization of aerosols over cities is important for the radiative balance calculations.

[4] To improve radiative transfer calculations, aerosol scattering and absorption properties need to be specified. These can be calculated when the particle size distribution (PSD), their indices of refraction and shape, are known. In addition, chemical composition is needed to calculate the refractive index of aerosols particles. Note that most aero- 
sols are nonabsorbing in the visible range. The two main atmospheric absorbing species are black carbon (the main constituent of soot) and hematite (a black iron oxide) [Horvath, 1998]. In Mie theory [van de Hulst, 1981; Bohren and Huffman, 1983], particle shape is assumed to be spherical. However, atmospheric aerosol particles are neither spherical nor homogeneous and therefore remain a challenge in atmospheric aerosol modeling. Today most aerosol applications rely on an optical model that treats aerosols as a mixture of spherical homogeneous particles of different sizes with a composition characterized by the complex refractive index. These assumptions typically allow models to adequately reproduce the observed aerosol affected radiation fields [Dubovik et al., 2002]. Recently, progress was made in modeling light scattering by nonspherical particles [e.g., Mishchenko, 2000; Mishchenko et al., 2000]. In principle, the nonsphericity can be determined by lidars which measure the depolarization ratio, i.e., the ratio between perpendicular and parallel-polarized light components (in media where multiple scattering depolarization is negligible).

[5] The vertical distribution and composition of aerosols and their optical properties are needed for the radiative transfer equations. To characterize temporal and spatial distribution of the aerosol optical characteristics of the atmosphere, lidar methods are very useful [e.g., Collis and Russell, 1976; Sassen et el., 1989; Sassen and Cho, 1992; Hoff et al., 1996; Marenco et al., 1997; Upendra et al., 1998; Welton et al., 2002; Pahlow et al., 2004b]. Elastic backscatter lidar is a powerful remote sensing tool that produces one-dimensional (1-D) to 3-D qualitative maps of the relative concentration and distribution of the aerosols over a region from which optical parameters can be determined. Since lidars provide data on both high spatial and temporal resolution, air motion can also be monitored since the concentration and spatial variability of aerosols can be used as a tracer [e.g., Mayor and Eloranta, 2001].

[6] In some cases, airborne measurements of the aerosols are available and direct characterization is feasible. For example, aircraft data taken during the Tropospheric Aerosol Radiative Forcing Observational Experiment (TARFOX) experiments were used to retrieve the particle complex index of refraction using aircraft data [Redemann et al., 2000]. A complete set of experiments to determine the aerosol spatial distribution and optical properties was conducted in the framework of Aerosol Characterization Experiment (ACE). ACE-2 over the Atlantic Ocean, for example, measured the particle size distribution, aerosol optical depth (AOD) (using a Sun photometer), aerosol extinction coefficient (using a lidar), and scattering coefficient (using a nephelometer) [Flamant et al., 2000].

[7] The Baltimore Supersite project provided an excellent opportunity to study urban aerosols and its optical properties. Herein, surface level scattering and vertical profiles of extinction are discussed for the 4-12 July 2002 period, which includes a major haze event due to Canadian forest fires (7-8 July 2002). During this period, aerosol size distribution, surface aerosol scattering, lidar, aerosol composition, and meteorological parameters were measured at temporal resolutions rang- ing from $5 \mathrm{~min}$ to 1 hour. This presented an excellent opportunity to characterize atmospheric optical properties under typical urban atmospheric conditions existing before the smoke episode and to compare them with those of the forest fire period characterized by soot dominated atmospheric aerosol.

[8] The visual range is first computed since it is directly related to the aerosol content. The key parameter that determines the influence of aerosols on visibility is the aerosol light extinction coefficient. Elterman [1970] conducted classical work on the meteorological range (or visual range) related to molecular and aerosol extinction and ozone absorption for different wavelengths (ranging from 0.27 to $2.17 \mu \mathrm{m}$ ) and different altitudes (ranging from 0 to $50 \mathrm{~km}$ ). This study is a basic reference for work that relates to the effect of aerosols on visibility.

[9] In our paper the vertical profiles of the aerosol extinction coefficient are determined by employing a nearend approach to solve the lidar equation using ground-based measurements for the near-end boundary value in the lidar equation. In addition, the aerosol scattering coefficients measured by a nephelometer and computed with Mie theory are analyzed and compared, and aerosol derived mass concentrations and aerosol mass scattering coefficients are calculated for the period.

\section{Experiment}

[10] The 2002 summer field campaign took place in an urban area in east Baltimore. The period investigated in this paper is 4-12 July 2002, which includes a haze event due to smoke originating in Canadian forest fires (arrival in Baltimore: 7-8 July). The aerosol scattering coefficient was measured with an integrating nephelometer (Radiance Research model M903), the particle number size distribution was obtained with a combination of scanning mobility particle sizer (SMPS) (model TSI, differential electrical mobility particle analyzer DMA 3081, sheath air flow $6 \mathrm{~L} / \mathrm{min}$ and aerosol flow $0.6 \mathrm{~L} / \mathrm{min}$ ) with 53 channels and a 52 channel aerodynamic particle sizer (APS). The SMPS covers a range of particle sizes from 0.00931 to $0.437 \mu \mathrm{m}$ and the APS 0.490 to $20.535 \mu \mathrm{m}$, hence spanning a total range from 0.00931 to $20.535 \mu \mathrm{m}$. The integrating nephelometer was operated at $0.530 \mu \mathrm{m}$ and provided the aerosol scattering coefficient with a detection limit of $0.001 \mathrm{~km}^{-1}$. The procedure for computing the aerosol scattering takes into account Rayleigh scattering by molecules. The nephelometer has sensors for pressure $p$, temperature $T$, and relative humidity $\mathrm{RH}$, such that the Rayleigh scattering coefficient is corrected for the actual $p$ and $T$. The Johns Hopkins University (JHU) lidar system consists of a Q-switched Nd-YAG laser (BigSkyLaser, model CFR 400) operated at $1.064 \mu \mathrm{m}$ (repetition rate $30 \mathrm{~Hz}$, maximum output $324 \mathrm{~mJ} /$ pulse, $10 \mathrm{~ns}$ pulse duration, $1.8 \mathrm{mrad}$ divergence), a Cassegrain telescope (Meade LX 50, f/10, diameter $25.4 \mathrm{~cm}, 5 \mathrm{mrad}$ divergence), a periscope, a photodetector (IR-enhanced Si avalanche photodiode), power supply, cooling system, and a computer for data acquisition. During this measurement campaign, we chose a $3.75 \mathrm{~m}$ spatial resolution (corresponding to $25 \mathrm{~ns}$ detector sampling duration). The lidar was pointing straight up during the entire measure- 
ment period. The zone of incomplete overlap in the case of the actual biaxial configuration was $\sim 300 \mathrm{~m}$.

\section{Methodology}

[11] The lidar equation can be written as

$$
P(r)=\frac{C}{r^{2}} \beta(r) \exp \left(-2 \int_{0}^{r} \kappa\left(r^{\prime}\right) d r^{\prime}\right),
$$

where $P(r)$ is the received backscattered energy by the photoreceiver $[\mathrm{J}]$ as a function of range $r ; C$ is the lidar constant $\left(C \sim A_{t} c t_{p} P_{0} / 2\right)$, which accounts for effective area of the receiving telescope $A_{t}\left[\mathrm{~m}^{2}\right]$, speed of light $c\left[\mathrm{~ms}^{-1}\right]$, pulse duration $t_{p}[\mathrm{~s}]$, outgoing laser energy per pulse $P_{0}[\mathrm{~J}]$, and also accounts for the photodetector efficiency; $\beta(r)$ is the backscatter coefficient $\left[\mathrm{m}^{-1} \mathrm{sr}^{-1}\right]$; and $\kappa(r)$ is the extinction coefficient $\left[\mathrm{m}^{-1}\right]$ for two atmospheric components (molecular and particulate).

[12] A more complete expression of the lidar equation has two additional terms that account for the multiple scattering (MS) and for background signal. In the present description the background signal has been subtracted from the total received energy, and we assume that MS does not occur. Ackermann et al. [1999] studied numerically the influence of MS on the retrieval of the extinction coefficient of tropospheric aerosols. In their simulations the extinction coefficient was assumed to be a constant within the atmospheric boundary layer (ABL) (the values chosen were $15.65,3.91,1.96,0.783$, and $0.078 \mathrm{~km}^{-1}$ ) and with an exponential decay above the ABL. They found that the contribution of MS on the lidar signal in such situations is typically less than $10 \%$ and never exceeds $20 \%$. Note that the relative error of the MS on the retrieved aerosol extinction profile in the ABL is found to be less than 3\% for all aerosols types, including urban environments. Thus, in the lidar equation, we have one equation and three unknowns, $C, \beta(r)$, and $\kappa(r)$. There are several approaches to solve the underdetermined lidar equation, which take into account additional information from either supporting instruments or theoretical estimates. Additional measurements of the aerosols may include determination of the reference values of the extinction coefficient, optical depth, PSD, etc. [see Klett, 1985; Weinman, 1988; Hoff et al., 1996; Redemann et al., 1996; Marenco et al., 1997; Flamant et al., 2000; Barnaba and Gobbi, 2001; Gobbi et al., 2002, 2003; Kovalev, 2003].

[13] When determining the extinction coefficient in a two-component atmosphere, it is generally assumed that molecular backscattering and extinction coefficients are known (e.g., computed from the Standard Atmosphere 1976 [NASA, 1976]). As follows from various studies [Fernald, 1984; Klett, 1985; Weinman, 1988; Sassen et al., 1989; Kovalev and Moosmüller, 1994; Flamant et al., 2000; Gobbi et al., 2002; Kovalev, 2003], the particulate extinction in this case can be found from

$$
\kappa_{p}(r)=\frac{P(r) r^{2} \exp \left(2(1-a) \int_{0}^{r} \kappa_{m}\left(r^{\prime}\right) d r^{\prime}\right)}{C \Pi_{p}-2 \int_{0}^{r} P\left(r^{\prime}\right) r^{\prime 2} \exp \left(2(1-a) \int_{0}^{r \prime} \kappa_{m}\left(r^{\prime \prime}\right) d r^{\prime \prime}\right) d r^{\prime}}-a \kappa_{m}(r),
$$

where $\kappa_{p}(r)$ represents the aerosol extinction coefficient at range $r, \kappa_{m}(r)$ represents the molecular extinction coefficient, $\left(\kappa=\kappa_{p}+\kappa_{m}\right)$ the ratio $a=\Pi_{m} / \Pi_{p}$ where $\Pi_{m}(3 / 8 \pi)$ is the molecular backscatter to extinction ratio, and $\Pi_{p}$ is the particulate backscatter to extinction ratio. Note that the solution to equation (2), the same as all others presented in this section, is based on the assumption that the particulate backscatter-to-extinction ratio $\Pi_{p}$ is a constant over the lidar measurement range. This assumption is the most common assumption when inverting the elastic-lidar signals, and it is used in our analysis here. It should be mentioned that at $1.064 \mu \mathrm{m}$ the molecular backscatter in lower atmospheric layers generally is much smaller than aerosol backscatter, and an incorrect aerosol backscatter to extinction ratio $\Pi_{p}$ does not produce significant errors, at least in the zones where the approximation $\Pi_{p}=$ const is valid. In the zones where this assumption is not valid, a $\pm 20 \%$ change of the ratio produces approximately the same order of change $(15-25 \%)$ in the retrieved extinction coefficients. It is straightforward to show that the use of a constant $\Pi_{p}$ over an extended vertical profile, where the actual $\Pi_{p}$ varies from 0.04 to $0.05 \mathrm{sr}^{-1}$, induces errors in the retrieved extinction coefficient profile of $\sim 10 \%$. The use of a constant $\Pi_{p}$ over a region where the actual $\Pi_{p}$ varies as much as twice, from 0.02 to $0.04 \mathrm{sr}^{-1}$, induces the error of $\sim 30 \%$, etc. Various experimental studies were carried out concerning the vertical variability of the $\Pi_{p}$. It has been shown [e.g., Ferrare et al., 1998a, 1998b] that a significant change in the lidar ratio (LR) (or $\Pi_{p}$ ) mostly occurs above ABL. Sasano and Browell [1989] showed that backscatter profiles at $1.064 \mu \mathrm{m}$ are insensitive to the value of the lidar ratio for continental aerosols. In summation, generally one can expect moderate changes of $\Pi_{p}$, and accordingly, moderate distortions in the retrieved extinction coefficient profiles when using a constant $\Pi_{p}$ for the signal inversion in the lower atmosphere. In summary, for $1.064 \mu \mathrm{m}$, the extinction coefficient is much more sensitive to the boundary condition than to the lidar ratio [e.g., Althausen et al., 2000].

[14] To determine $\kappa_{p}(r)$ with equation (2), the value of $\Pi_{p}$ and the lidar constant $C$ must be determined. Generally, the solution for $\kappa_{p}(r)$ is found by using reference values rather than through direct determination of the constants $\Pi_{p}$ and $C$. In other words, $\kappa_{p}(\mathrm{r})$ can be found if the boundary conditions are known either at a local point or over some range.

[15] The most stable solution was proposed by Klett [1985]. To apply this solution, the boundary value of $\kappa_{p}\left(r_{m}\right)$ at some distant range $r_{m}$ should be known. In this case, equation (2) can be rewritten into the form

$$
\kappa_{p}(r)=\frac{P(r) r^{2} \exp \left(2(1-a) \int_{r}^{r_{m}} \kappa_{m}\left(r^{\prime}\right) d r^{\prime}\right)}{\frac{P\left(r_{m}\right) r_{m}^{2}}{\kappa_{p}\left(r_{m}\right)+a \kappa_{m}\left(r_{m}\right)}+2 \int_{r}^{r_{m}} P\left(r^{\prime}\right) r^{\prime 2} \exp \left(2(1-a) \int_{r^{\prime}}^{r_{m}} \kappa_{m}\left(r^{\prime \prime}\right) d r^{\prime \prime}\right) d r^{\prime}}-a \kappa_{m}(r) .
$$

There are different approaches used to determine the boundary condition $\kappa_{p}\left(r_{m}\right)$. One way is to assume a homogeneous atmosphere and to determine the boundary value using the slope method [Collis, 1966]. In clear atmospheres, the solution in equation (3) is practical only when the molecular contribution at distance $r_{m}$ has to be 
considered, i.e., some distant aerosol-free area exists where $\kappa_{p}\left(r_{m}\right)=0$.

[16] The alternative method known as the optical depth solution uses the total optical depth or the related transmittance over the total lidar measurement range as the boundary value when determining $\kappa_{p}(r)$ [Weinman, 1988; Marenco et al., 1997; Kovalev, 1995]. The most general form of the solution can be written

$$
\kappa_{p}(r)=\frac{0.5 P(r) r^{2} \exp \left(2(1-a) \int_{r_{0}}^{r} \kappa_{m}\left(r^{\prime}\right) d r^{\prime}\right)}{\frac{I_{\max }}{1-V_{\max }^{2}}-\int_{r_{0}}^{r} P\left(r^{\prime}\right) r^{\prime 2} \exp \left(2(1-a) \int_{r_{0}}^{r^{\prime}} \kappa_{m}\left(r^{\prime \prime}\right) d r^{\prime \prime}\right) d r^{\prime}}
$$

where $r_{0}$ is the minimum lidar measurement range

$$
\begin{gathered}
I_{\max }=\int_{r_{0}}^{r_{\max }} P\left(r^{\prime}\right) r^{\prime 2} \exp \left(2(1-a) \int_{r_{0}}^{r \prime} \kappa_{m}\left(r^{\prime \prime}\right) d r^{\prime \prime}\right) d r^{\prime}, \\
V_{\max }^{2}=\exp \left(-2 \int_{r_{0}}^{r_{\max }}\left[\kappa_{p}(r)+a \kappa_{m}(r)\right] d r\right),
\end{gathered}
$$

and $r_{\max }$ is the maximum lidar measurement range [Kovalev, 1995]. $V_{\max }^{2}$ is defined as the effective transmittance (the conventional transmittance being defined when $a=1$ ) as it is computed for the effective extinction coefficient $\kappa_{p}(r)+$ $a \kappa_{m}(r) . I_{\max }$ is the integral of the range-transformed signal over the total measurement range which together with $V_{\max }^{2}$ specifies the constant $(\mathrm{C})$ in the lidar equation $\left(I_{\max } /(1-\right.$ $\left.V_{\max }^{2}\right)=\mathrm{C} / 2$ ). For a vertically staring lidar with an extended measurement range $(>10 \mathrm{~km}), V_{\max }^{2}$ can be determined using a Sun photometer [see Weinman, 1988; Kovalev, 1995; Marenco et al., 1997; Flamant et al., 2000]. However, such a method is largely inappropriate for lidars with relatively small total measurement range $(5-7 \mathrm{~km})$. In this case, in situ measurements of the aerosol scattering made by a nephelometer can provide useful information when applying the optical depth solution [e.g., Flamant et al., 2000]. A variant of this method, known as the one angle method (OAM) was developed for clear atmospheres by Kovalev [2003] using a combination of the optical depth solution and a near-end constraint for the lidar equation. The solution relies on aerosol scattering measured at the lidar location at ground level using a nephelometer. It was also assumed in that study that no particulate absorption occurs. The scattering coefficient as measured by the nephelometer at $0.530 \mu \mathrm{m}$ is converted to $1.064 \mu \mathrm{m}$ with the Angstrom formula. The lidar scattering profile at the lowest end is extrapolated to the ground level scattering coefficient by linear regression. The numerical value of $\mathrm{V}_{\max }^{2}$ is varied until the extrapolated lidar near-end signal and the scattering coefficient from the nephelometer match. It should also be mentioned that there also exist combinations of far-end and optical depth solutions [e.g., Marenco et al., 1997].

[17] Here we develop a modified OAM procedure to invert the lidar equation using the near-end solution. The difference from Kovalev [2003] is that we do not only consider clear atmospheres, but also polluted atmospheres, so that we need to take into account aerosol absorption. The near-end boundary value is determined using measurements of the aerosol scattering coefficient at $0.530 \mu \mathrm{m}$ by a nephelometer, particle size distribution measured by SMPS, and APS instruments and Mie theory to indirectly determine the aerosol refractive index. The aerosol extinction coefficient at the lidar wavelength $(1.064 \mu \mathrm{m})$ at the ground level is computed using Mie theory. The operation steps are as following.

[18] We choose the index of refraction $m=n-i k$ such that the computed aerosol scattering coefficient using Mie theory (see the equation below) matches the measured one by nephelometer (Figure 1a). This is an indirect method to determine the refractive index. Here

$$
\begin{aligned}
\sigma_{p} & =\int_{r_{1}}^{r_{2}} \pi r^{2} n(r) Q_{\text {sca }}(m, r, \lambda) d r \\
& =\frac{\pi}{\ln (10)} \sum_{i}\left(\frac{\Delta N}{\Delta \log (d)}\right)_{i} \bar{r}-Q_{\text {sca }}(m, \bar{r}, \lambda) \Delta r,
\end{aligned}
$$

where $r_{1}$ and $r_{2}$ are the minimum and the maximum of the aerosol particle radius $r, n(r)$ is the number density (differential number size distribution, in $\mathrm{cm}^{-3} \mathrm{~cm}^{-1}$ ), $Q_{\text {sca }}$ is the scattering efficiency computed according to Mie theory [see van de Hulst, 1981; Bohren and Huffman, 1983], $\bar{r}$ is the mean radius of the $i$ th aerosol sampling channel, $\Delta r$ is the channel width, $m$ is the index of refraction, $\lambda$ is the wavelength $(0.530 \mu \mathrm{m})$, and $\Delta N$ is the number density in the particle diameter $(d)$ range $\Delta$ log $(d)$ $\left[\mathrm{cm}^{-3}\right]$. Once $m$ is determined, we calculate scattering, extinction, and backscattering coefficients at $\lambda=1.064 \mu \mathrm{m}$, as well as the aerosol backscatter-to-extinction ratio. The computed aerosol extinction coefficient at ground level is used as the boundary value in the lidar equation $\left(\kappa_{p}(r=0)\right)$. We assume that there is no dispersion between 0.530 and $1.064 \mu \mathrm{m}$ (i.e., index of refraction does not vary with wavelength). Once the boundary value and the aerosol backscatter to extinction ratio at ground level are obtained, we invert the lidar equation using equation (4). The integral is found over the range from $r_{0}$ to $r$. The main assumption is that the aerosol backscatter to extinction ratio (or lidar ratio) is range-independent for the vertical profile. For the molecular extinction coefficient we use Edlen's [1966] formula for the refractive index and a vertical decay function of pressure and temperature from the Standard Atmosphere 1976 [NASA, 1976].

[19] We select an apparent linear range of the aerosol extinction profile in the lidar near field and then extrapolate to the ground level $(r=0)$ such that

$$
\kappa_{p}\left(r_{0}\right)=\kappa_{p}(r=0)+b r_{0},
$$

where $b$ is the slope of the linear fit. The effective transmittance $V_{\max }^{2}$ is chosen such that the value of the extinction coefficient obtained from the lidar signal and extrapolated to the ground level matches the value determined by Mie theory.

[20] An initial guess of $V_{\max }^{2}\left(0<V_{\max }^{2}<1\right)$ in equation (4) is determined from

$$
V_{\text {max }, \text { init }}^{2}=1-\frac{2\left(a \kappa_{m}\left(r_{0}\right)+\kappa_{p}(r=0)\right)}{S\left(r_{0}\right)} \int_{r_{0}}^{r_{\max }} S\left(r^{\prime}\right) d r^{\prime}
$$




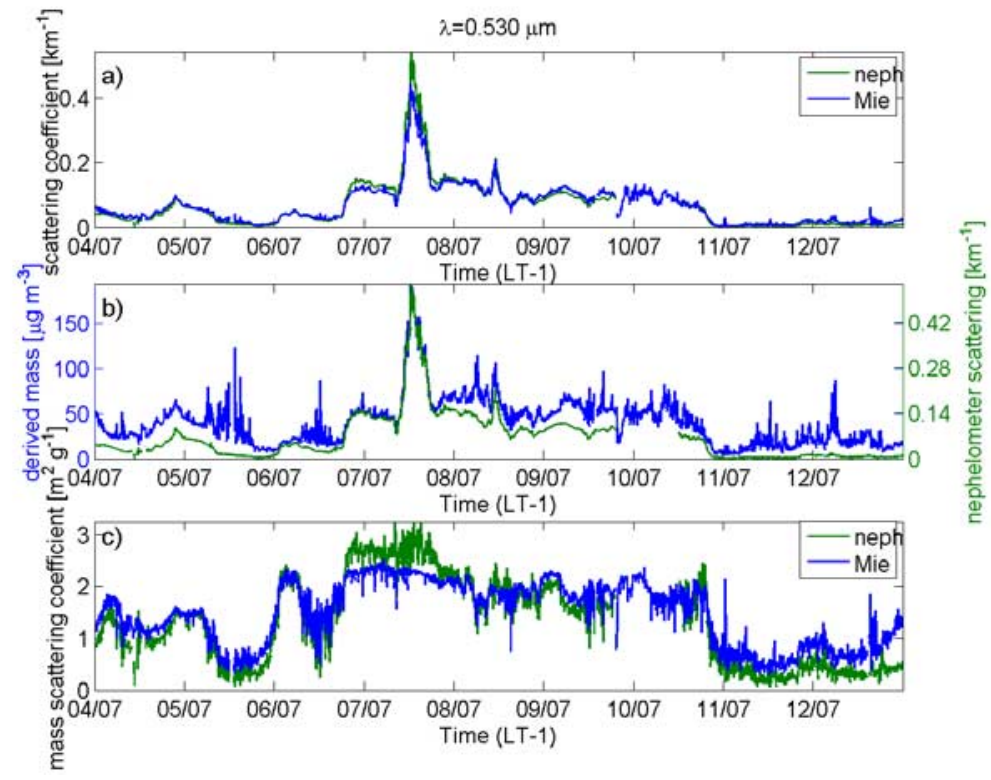

Figure 1. Temporal variation of the aerosol scattering coefficient as measured by nephelometer and computed by (a) Mie theory, (b) of the derived mass, and (c) of the mass scattering coefficient. Tick marks on the time axis correspond to midnight.

by assuming $\kappa_{p}\left(r_{0}\right)=\kappa_{p}(0)$. $S(r)$ represents the range corrected signal $\left(P(r) r^{2}\right)$. The procedure is illustrated in Figure 2.

\section{Results}

\subsection{Particle Size Distribution}

[21] In Figures $3 \mathrm{a}, 3 \mathrm{~b}$, and $3 \mathrm{c}$ the particle number, the particle surface area, and the particle volume are presented, respectively. Particle number peaks usually below $0.1 \mu \mathrm{m}$ (nucleation region: nucleation and fresh combustion particles). During the haze event ( 7 and 8 July), the particle surface area peaks between 0.6 and $0.7 \mu \mathrm{m}$ (which corresponds to an increase in aerosol scattering), and particle volume peaks at $0.7 \mu \mathrm{m}$ (which corresponds to derived mass increase). The scattering coefficient $\sigma_{p}(r)=($ particle surface area $) \times(1 / \ln (10))(\Delta r / r)$, where the particle surface area $=($ particle number $) \times\left(\pi \mathrm{d}^{2} / 4\right)$ and $(\Delta r / r) \sim 0.0729$.

[22] In Figure 4 the average and the standard deviation of particle number (Figure 4a), particle surface area (Figure 4b), and particle volume (Figure 4c) for the time period separated into "before," "during," and "after" the haze event. The large standard deviation reflects the strong variations during each period. In the first period, particle number is predominantly within the range $[0.01-$ $0.2] \mu \mathrm{m}$ and peaks at $\sim 0.04 \mu \mathrm{m}$. The maximum of the daily mean occurs on 5 July $\left(15,000 \mathrm{~cm}^{-3}\right)$. During the second period (haze event), the particle number increases and the peak shifts toward $\sim 0.015 \mu \mathrm{m}$. The maximum daily mean occurs during 8 July $\left(20,000 \mathrm{~cm}^{-3}\right)$. During the last period the particle number remains high but the peak shifts to $0.04 \mu \mathrm{m}$. The maximum of the daily mean occurs on 11 July $\left(17,000 \mathrm{~cm}^{-3}\right)$. The surface area peaks at $0.2 \mu \mathrm{m}$ in the first period (a second peak occurred at $\sim 0.7 \mu \mathrm{m}$ ), the maximum of the daily mean being on
6 July $\left(\sim 110 \mu \mathrm{m}^{2} \mathrm{~cm}^{-3}\right)$. Surface area increases during the second period (smoke period) and peaks at $0.6-$ $0.7 \mu \mathrm{m}$ (with a second peaks at $0.1-0.2 \mu \mathrm{m}$ ). The maximum of the daily mean occurs on 7 July $\left(450 \mu \mathrm{m}^{2} \mathrm{~cm}^{-3}\right)$. During the third period, surface area decreases and peaks at $0.1 \mu \mathrm{m}$ (the maximum of the daily mean on 12 July is $\left.100 \mu^{2} \mathrm{~cm}^{-3}\right)$. The particle volume includes many peaks during the first period with a maximum at $0.6 \mu \mathrm{m}$ (maximum of the daily mean on 6 July of $47 \mu^{3} \mathrm{~cm}^{-3}$ at $0.6 \mu \mathrm{m})$. During the second period, particle volume increases and has a peak at $0.7 \mu \mathrm{m}$ (maximum of the daily mean on 7 July is $200 \mu \mathrm{m}^{3} \mathrm{~cm}^{-3}$ at $\sim 0.7 \mu \mathrm{m}$ ). During the third period, particle volume decreases and

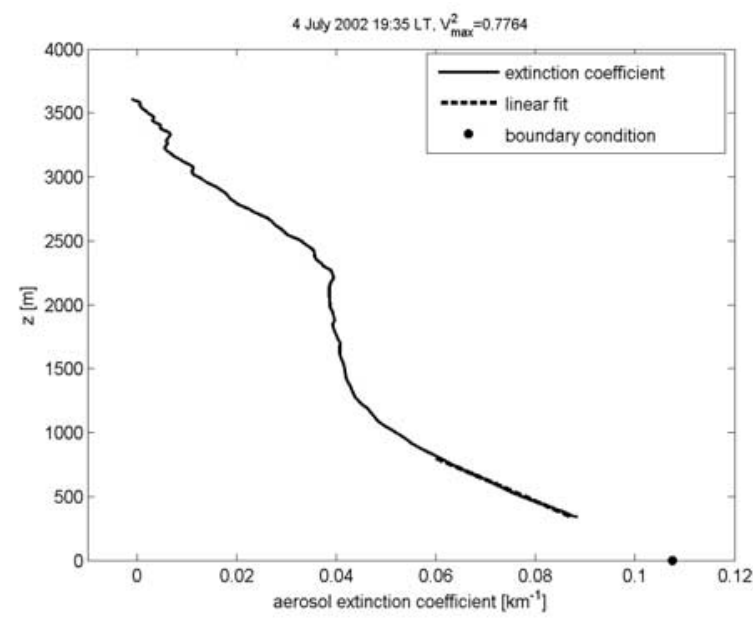

Figure 2. Example of retrieving the vertical profile of the aerosol extinction coefficient by choosing the corresponding $V_{\max }^{2}$. 

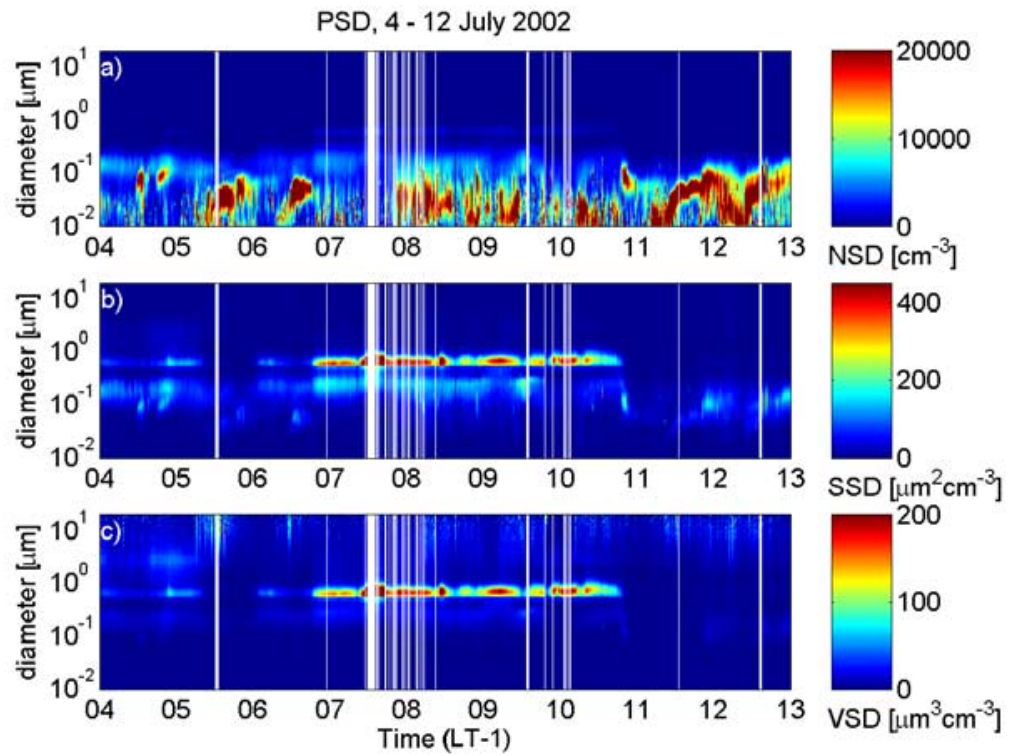

Figure 3. Temporal variation of the particle size distribution (PSD); (a) particle number (NSD), (b) particle surface area (SSD), and (c) particle volume (VSD).

peaks at $10 \mu \mathrm{m}$ (maximum daily mean $\sim 20 \mu \mathrm{m}^{3} \mathrm{~cm}^{-3}$ on both 11 and 12 July).

\subsection{Aerosol Scattering Coefficient}

[23] The aerosol scattering coefficients for 4-12 July measured and computed at $\lambda=0.530 \mu \mathrm{m}$ (equation (7)) are shown in Figure 1a. The retrieved value of the index of refraction is that of soot (i.e., for $\lambda=0.550 \mu \mathrm{m}, m=$ $1.5-0.47 i$ [Horvath, 1998]), which is consistent with the proximity of the field site next to major highways and urban traffic. A commonly used value for the refractive index for aerosols in a polluted area is $m=$ $1.5-0.1 i$ (at $550 \mathrm{~nm}$, corresponding to mixed absorbing particles [e.g., Horvath, 1998]). Under these conditions, considering $m=1.5-0.47 i, \lambda=0.530 \mu \mathrm{m}$ and particle size distribution (measured) ranging from $10 \mathrm{~nm}$ to $20 \mu \mathrm{m}$, the scattering efficiency $Q_{\text {sca }}$ increases from 0 to $\sim 1.2$ for particle diameters $\geq 0.5 \mu \mathrm{m}$. It is 1 for particles with diameters $\sim 0.35 \mu \mathrm{m}, 0.5$ for particles with diameter of $\sim 0.2 \mu \mathrm{m}$, and decreases sharply for smaller

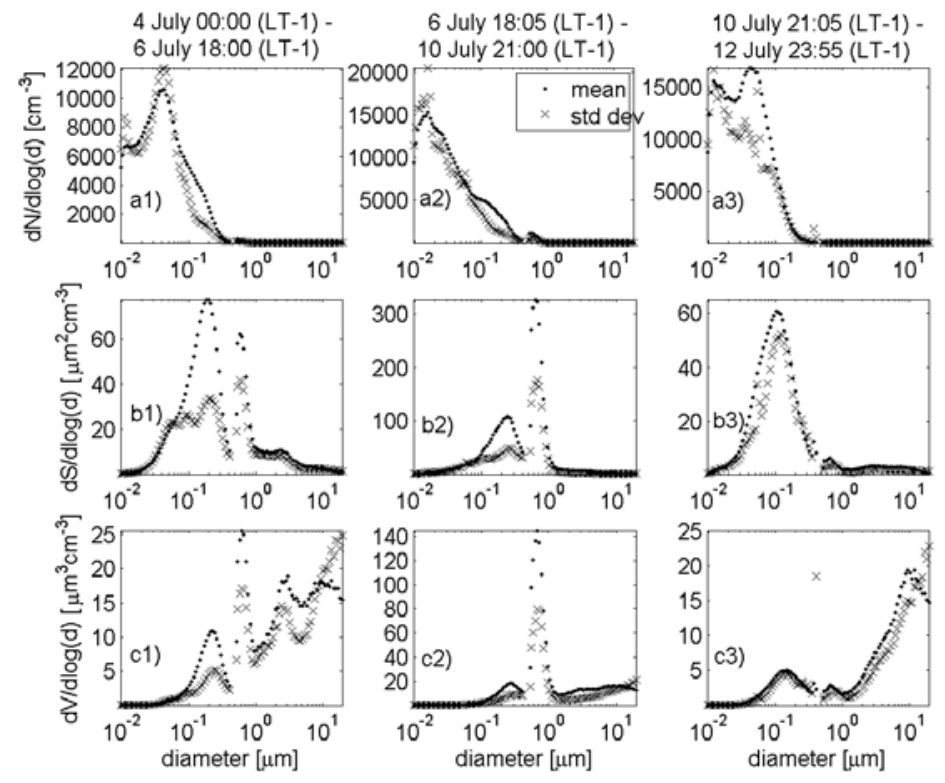

Figure 4. Mean (dots) and standard deviation (crosses) of the particle size distribution over the three time periods under investigation $(1,2$, and 3 are the three periods; and $\mathrm{a}, \mathrm{b}$, and $\mathrm{c}$ stand for particle number, surface area, and volume, respectively). 
Table 1. Correlation Coefficients Between Measured and Computed Aerosol Scattering and Between Measured Aerosol Scattering and Mass Concentration

\begin{tabular}{|c|c|c|c|c|c|c|c|c|c|c|}
\hline & 4 July & 5 July & 6 July & 7 July & 8 July & 9 July & 10 July & 11 July & 12 July & 4-12 July \\
\hline $\mathrm{Eed}$ & 0. & 0 & 0.99 & 0 . & 0 & 0.5 & 0. & 0 . & .5.5 & 0 . \\
\hline easured aerosol scattering & 0.86 & 0.51 & 0.84 & 0.98 & 0.82 & 0.42 & 0.91 & 0.49 & 0.54 & 0.91 \\
\hline
\end{tabular}

particles. In other words, the contribution to the scattering coefficient comes from particles with large surface area or large scattering efficiency (both are large during the second period 6-10 July). The maximum extinction efficiency $(\sim 2.6)$ occurs for particles with a diameter of $0.5 \mu \mathrm{m}$, an efficiency of 1 corresponds to particles of $0.15 \mu \mathrm{m}$, and an efficiency of 0.5 corresponds to particles of $0.08 \mu \mathrm{m}$.

[24] The overall correlation coefficient for the entire period between measured and computed scattering coefficient is 0.98 (see Table 1). A high correlation coefficient is of course expected because the refractive index was chosen such that the agreement between measured and computed aerosol scattering coefficient was the greatest. The correlation coefficients for each individual day are also presented in Table 1. A weak correlation was found for 12 July, when the computed aerosol scattering coefficient shows large fluctuations which correspond to large variations in PSD. Note that a first peak in the scattering coefficient was observed during the night of 4 July, owing to fireworks that locally increased the aerosol concentrations. The scattering coefficient increased again during the evening of 6 July, the onset of the haze event (due to the forest fires). The largest scattering coefficient was recorded on 7 July, around noon $(1335 \mathrm{LT})$, with $\sigma_{p}=0.540 \mathrm{~km}^{-1}$. A second peak with $\sigma_{p}=0.215 \mathrm{~km}^{-1}$ was recorded on 8 July again around noon (1225 LT). The scattering coefficient remains high $\left(>0.1 \mathrm{~km}^{-1}\right)$ until the beginning of a rainstorm on 9 July ( 2030 LT). Owing to the storm, no data were recorded until the afternoon of 10 July. The values recorded at that time were still high, but they decreased during the night of 10 July. The extinction coefficient $\kappa_{p}$ maximum value of $1.05 \mathrm{~km}^{-1}$ was obtained on 7 July 1335 LT.

[25] Statistics for the measured and computed aerosol scattering coefficients as well as computed aerosol extinction coefficients are presented in Table 2. The total period analyzed here was divided into three intervals as follows. The intervals 4 July at 0100 LT to 6 July at 1900 LT, 6 July at 1905 LT to 10 July at 2200 LT, and 10 July at 2205 LT to 13 July at 0055 LT corresponds to presmoke, smoke, and postsmoke periods. The influence of the smoke as a result of mixing into the ABL can be seen in Figure 1 and Table 2, especially during the peak period on 7 July. The average value of the scattering coefficient during the haze event (second interval) was 4 times larger than for the first period and 21 times larger than for the third period (see Table 2). The ratio of aerosol absorption $\left(\kappa_{\mathrm{p}}-\sigma_{\mathrm{p}}\right)$ to aerosol scattering $\left(\sigma_{\mathrm{p}}\right)$ coefficient varies during the three periods due to different elemental carbon fraction in the aerosol. Smaller absorption coefficients can occur when other chemical components dominate over elemental carbon. For example, during the haze event, a large contribution to the aerosol loading came from the smoke layer, mainly as organic carbon.

[26] It is interesting to compare these measurements taken during the Baltimore PM Supersite experiment with results from other Supersite studies. For instance, the Atlanta Supersite Experiment [Carrico et al., 2003] shows an average and standard deviation for measured (integrating nephelometer M903, Radiance Research) aerosol scattering of $\sigma_{p}=0.121 \pm 0.048 \mathrm{~km}^{-1}$ (average over entire period of study, 30 July to 3 September 1999). They measured absorption (particle soot absorption photometer, Radiance Research) and obtained $\alpha_{p}=0.016 \pm 0.012 \mathrm{~km}^{-1}$. This gives an extinction coefficient of $\kappa_{p}=0.137 \pm 0.06 \mathrm{~km}^{-1}$. The absorption coefficient found in the present study is large compared with that found during the Atlanta Supersite [Carrico et al., 2003], which could be related to the proximity of the Baltimore site to highways.

\subsection{Particle Derived Mass Concentration}

[27] Figure $1 \mathrm{~b}$ represents the temporal variation of the particle mass concentration (termed "derived mass" by Hoff et al. [1996]) and the temporal variation of the aerosol scattering coefficient measured by the nephelometer. The mass concentration is defined

$$
M(V, \rho)=V \rho,
$$

where $M$ is in $\left[\mu \mathrm{g} \mathrm{cm}^{-3}\right], V$ represents the particle volume in $\left[\mu \mathrm{m}^{3} \mathrm{~cm}^{-3}\right]$ (derived from particle number), and $\rho$ is the particle density in $\left[\mathrm{g} \mathrm{cm}^{-3}\right]$. The corresponding value for $\rho$ is chosen to be equal to $1.0 \mathrm{~g} \mathrm{~cm}^{-3}$, representative for soot [Horvath, 1998]. The correlation between mass concentration and the measured aerosol scattering is given in Table 1. The overall correlation coefficient was $R=0.91$. A small correlation coefficient was found on days where the mass concentration showed large variation (owing to the variation recorded in PSD). On the last two days the low correlation might be related to the nephelometer which recorded values close to the detection limit. As expected, the derived mass concentration increased during the smoke event (see Table 2). The maximum of $194 \mu \mathrm{g} \mathrm{m}^{-3}$ occurred at 1330 LT on 7 July. This is in broad agreement with the values of 162.65 and $197.94 \mu \mathrm{g} \mathrm{m}^{-3}$ measured with the Tapered Element Oscillating Microbalance (TEOM) PM2.5 as the average from 1300 to 1330 and from 1330 to 1400 LT (see the paper by Pahlow et al. [2004a]).

\subsection{Particle Mass Scattering Coefficient}

[28] Figure 1c represents the temporal variation of the mass scattering coefficient $\left[\mathrm{m}^{2} \mathrm{~g}^{-1}\right.$ ] (or "specific scattering coefficient" [Horvath, 1998] or "light scattering efficiency" [Sloane, 1986]). The mass scattering coefficient is defined as the ratio between scattering coefficient and mass concentration of the aerosol [Charlson, 1969] or 
Table 2. Mean, Standard Deviation, Maximum, Minimum, and Median for Measured (Nephelometer) and Computed (Mie Theory) Aerosol Scattering, Computed (Mie Theory) Aerosol Extinction Coefficient, Derived Mass, and Mass Scattering Coefficient (Using Measured and Computed Scattering Coefficient)

\begin{tabular}{|c|c|c|c|}
\hline & $\begin{array}{l}4 \text { July } 0100 \text { LT to } \\
6 \text { July } 1900 \text { LT }\end{array}$ & $\begin{array}{l}6 \text { July } 1905 \text { LT to } \\
10 \text { July } 2200 \text { LT }\end{array}$ & $\begin{array}{l}10 \text { July } 2205 \text { LT to } \\
13 \text { July } 0055 \text { LT }\end{array}$ \\
\hline \multicolumn{4}{|c|}{ Measured Aerosol Scattering $\sigma_{p}, \mathrm{~km}^{-1}$ (Nephelometer) } \\
\hline Mean & 0.032 & 0.126 & 0.006 \\
\hline Standard deviation & 0.019 & 0.080 & 0.003 \\
\hline Minimum & 0.002 & 0.007 & 0.002 \\
\hline Maximum & 0.095 & 0.541 & 0.018 \\
\hline Median & 0.032 & 0.107 & 0.005 \\
\hline \multicolumn{4}{|c|}{ Computed Aerosol Scattering $\sigma_{p}, \mathrm{~km}^{-1}$ (Mie Theory) } \\
\hline Mean & 0.039 & $0.126^{\circ}$ & 0.013 \\
\hline Standard deviation & 0.020 & 0.066 & 0.007 \\
\hline Minimum & 0.006 & 0.010 & 0.003 \\
\hline Maximum & 0.104 & 0.467 & 0.060 \\
\hline Median & 0.037 & 0.113 & 0.012 \\
\hline \multicolumn{4}{|c|}{ Computed Aerosol Extinction $\kappa_{p}, \mathrm{~km}^{-1}$ (Mie Theory) } \\
\hline Mean & 0.107 & 0.306 & 0.047 \\
\hline Standard deviation & 0.049 & 0.146 & 0.027 \\
\hline Minimum & 0.024 & 0.045 & 0.010 \\
\hline Maximum & 0.267 & 1.05 & 0.206 \\
\hline Median & 0.103 & 0.282 & 0.042 \\
\hline \multicolumn{4}{|c|}{ Derived Mass $M, \mu g m^{-3}$} \\
\hline Mean & 30.1 & 59.6 & 17.3 \\
\hline Standard deviation & 14.5 & 27.0 & 9.83 \\
\hline Minimum & 7.69 & 10.3 & 3.96 \\
\hline Maximum & 123 & 194 & 86.9 \\
\hline Median & 26.5 & 53.4 & 15.5 \\
\hline \multicolumn{4}{|c|}{ Mass Scattering $\sigma_{p} / M, m^{2} g^{-1}$ (Nephelometer) } \\
\hline Mean & 1.1 & 2.05 & 0.365 \\
\hline Standard deviation & 0.533 & 0.495 & 0.147 \\
\hline Minimum & 0.071 & 0.469 & 0.058 \\
\hline Maximum & 2.42 & 3.26 & 0.921 \\
\hline Median & 1.10 & 2 & 0.348 \\
\hline \multicolumn{4}{|c|}{ Mass Scattering $\sigma_{p} / M, m^{2} g^{-1}$ (Mie Theory) } \\
\hline Mean & 1.34 & 2.08 & 0.762 \\
\hline Standard deviation & 0.470 & 0.270 & 0.248 \\
\hline Minimum & 0.354 & 0.794 & 0.315 \\
\hline Maximum & 2.41 & 2.61 & 2.16 \\
\hline Median & 1.38 & 2.1 & 0.715 \\
\hline
\end{tabular}

change in particle scattering per unit aerosol mass [Hoff et al., 1996]. Hence this parameter is a measure of the effectiveness with which aerosol particles interact with light. The mass scattering coefficient also varies with particle diameter. The mass extinction remains constant if the PSD always has the same shape (other pertinent aerosol characteristics being fixed). This is called "selfpreserving size distribution"[Charlson, 1969]. As the PSD changes, the mass extinction will not remain constant. In our study the mass scattering coefficient ranges from 0.058 to $3.260 \mathrm{~m}^{2} \mathrm{~g}^{-1}$ (see Figure 1c and Table 2). The statistics for each interval are shown in Table 2. Tremendous changes in ambient aerosol characteristics, mostly due to the forest fire smoke, are reflected in the large change in the mass scattering coefficient which strongly increases during the second period 6 July 1900 LT to 10 July 2200 LT.

[29] Hoff et al. [1996] describe an experiment carried out in Ontario, Canada, where a haze event was observed and they measured an average mass scattering of $3.2 \mathrm{~m}^{2} \mathrm{~g}^{-1}$ (the observed range was $1-10 \mathrm{~m}^{2} \mathrm{~g}^{-1}$ ) assuming a mean particle density of $2.0 \mathrm{~g} \mathrm{~cm}^{-3}$. During the Atlanta Supersite Experiment [Carrico at al., 2003], a range between 3.5 and $4.4 \mathrm{~m}^{2} \mathrm{~g}^{-1}$ was found (a mean particle density of $1.5 \mathrm{~g} \mathrm{~cm}^{-3}$ was used). The different ranges for these two previous studies and the present one arise in part from the different particle density assumptions. These assumptions are based on the particle chemical composition. Furthermore, derived mass depends also on the particle volume distribution, which may be quite different from one location to another.

\subsection{Visibility Calculations}

[30] A first characterization of the aerosol extinction is made considering the visibility criteria [e.g., Elterman, 1970]. The clear-haze regime delimitation is defined at $15 \mathrm{~km}$ [Hulbert, 1941], which corresponds to aerosol extinction $\kappa_{p} \sim 0.26 \mathrm{~km}^{-1}$ at $\lambda=0.550 \mu \mathrm{m}$. Figure 5 shows the result for the visibility calculations, determined as a function of molecular and aerosol extinction at $0.530 \mu \mathrm{m}$. The procedure used was based on the Koschmieder formula [see Elterman, 1970], which relates the aerosol extinction 


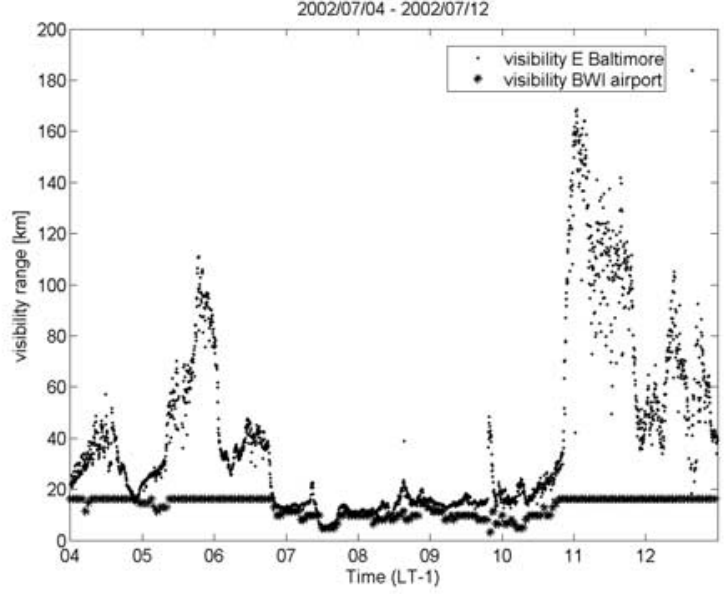

Figure 5. Visibility at Baltimore and BWI Airport.

at $\lambda=0.550 \mu \mathrm{m}$ to the visual range. Herein we use the aerosol extinction coefficient computed with Mie theory at $\lambda=0.530 \mu \mathrm{m}$. On the same graph the visibility was determined at BWI Airport is shown, located $15 \mathrm{~km}$ south of Baltimore (based on measurements of the aerosol forward scattering). Note that at BWI Airport, as at all civil airports, only poor visibility events are actually recorded. High visibilities are simply reported as equal to $16 \mathrm{~km}$. On the basis of our computations, the atmosphere was clear on $4,5,6,11$, and 12 July (visibility $>15 \mathrm{~km}$ ) and hazy on 7, 8, 9 July. The 10th of July was characterized by visual ranges between clear and hazy regime limits.

\subsection{Vertical Aerosol Extinction Coefficient}

[31] The vertical aerosol extinction coefficient profiles retrieved from the lidar data are given in Figures 6-10 for 5, 7, 8, 9, and 12 July, respectively. Figures $6 a, 7 a, 8 a, 9 a$, and 10a represent the time series of the lidar range corrected signal (color scale in arbitrary units) and the corresponding aerosol extinction coefficients (color scale represents the aerosol extinction coefficient in $\mathrm{km}^{-1}$ ). Figures $6 c, 7 c, 8 c, 9 c$, and $10 \mathrm{c}$ show vertical profiles of the aerosol extinction coefficient at different times of the day. Note that the vertical profiles of the extinction coefficient are averages over periods of $\sim 30 \mathrm{~min}$. In Figures $6 \mathrm{~b}, 7 \mathrm{~b}, 8 \mathrm{~b}, 9 \mathrm{~b}$, and $10 \mathrm{~b}$, values of the backscatter to extinction ratio $\Pi_{p}$ are shown (right $y$ scale in $\mathrm{sr}^{-1}$ ). With one exception (on 12 July $1800 \mathrm{LT}$ ), $\Pi_{p}$ ranges between 0.0431 and $0.0726 \mathrm{sr}^{-1}$ with a mean and standard deviation of $0.0547 \pm 0.0070 \mathrm{sr}^{-1}$. This corresponds to a mean lidar ratio of $18 \mathrm{sr}$.

[32] Vertical extinction profile computations, in general, were made for selected lidar profiles taken in cloud-free conditions. Cloud-free conditions prevail on $5,7,8$, and 12 July. We present profile results for just five of the measurement days.

[33] The profiles obtained on 5 July are shown in Figure 6 . The maxima of the particle extinction coefficient occurred at the beginning of the day and at noon, when thermals mix aerosols into the ABL, which can be seen in the lidar range corrected signals (Figure 6a).
A large extinction is recorded at noon (1313 LT), which corresponds to the thermal seen in the range corrected signal (Figure 6a). During this period, the ABL height was between 1500 and $1700 \mathrm{~m}$ from 1200 to $1900 \mathrm{LT}$.

[34] On 7 July, just a few profiles could be determined which correspond to times before and after the smoke was entrained into the ABL (see Figure 7a). It must be noted that the method used here to retrieve the extinction
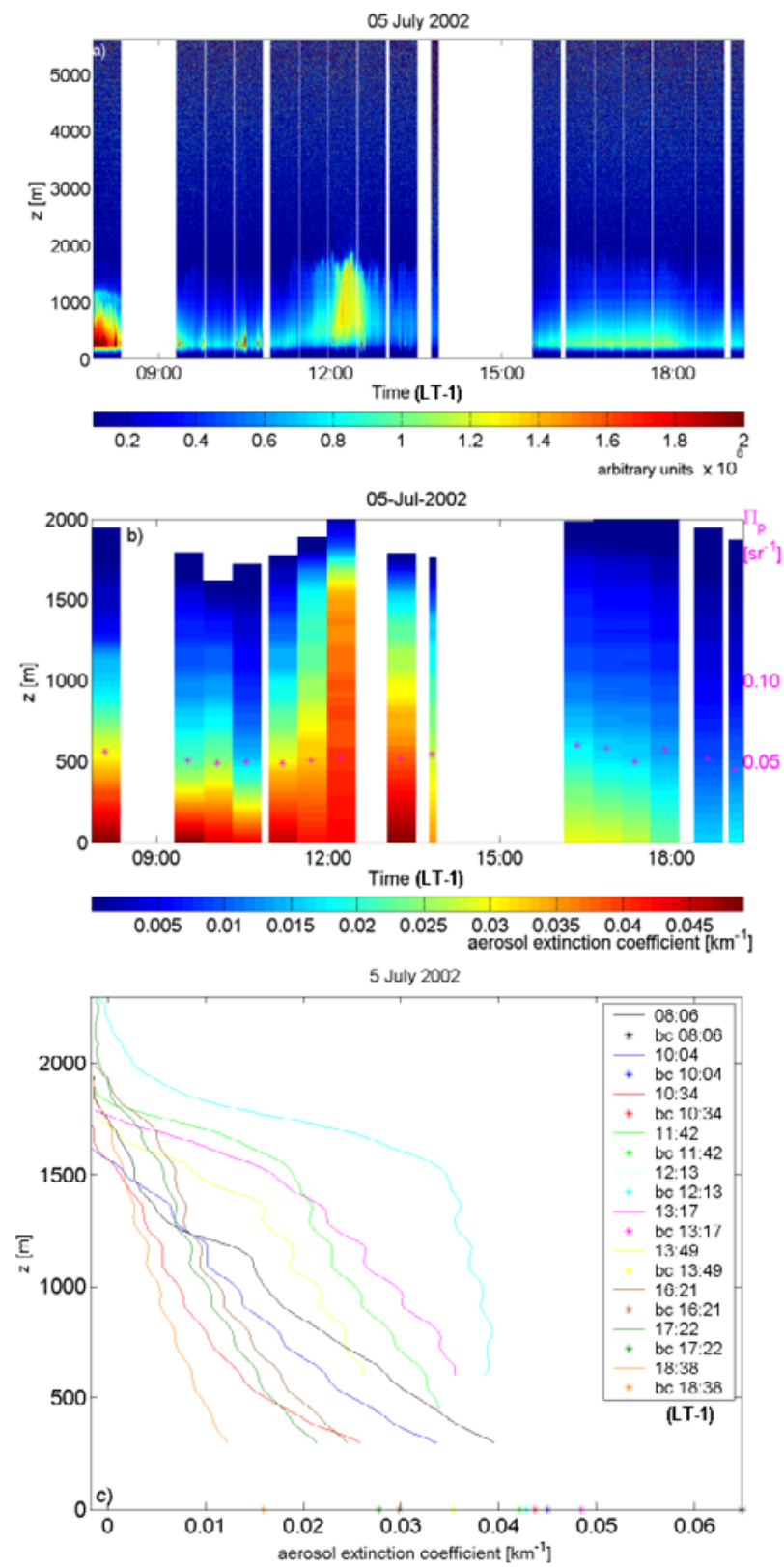

Figure 6. (a) Temporal vertical profile of the lidar range corrected signal (the color scales represent the rangecorrected signal in arbitrarily selected units). (b) Temporal vertical profile of the aerosol extinction coefficient (the aerosol extinction coefficient in $\mathrm{km}^{-1}$ ); on the right axis, backscatter to extinction ratio $\Pi_{\mathrm{p}}\left(\mathrm{sr}^{-1}\right)$ (asterisks). (c) Vertical profile of the aerosol extinction coefficient at different time stamps (LT - 1) for 5 July 2002 (bc, boundary condition). 

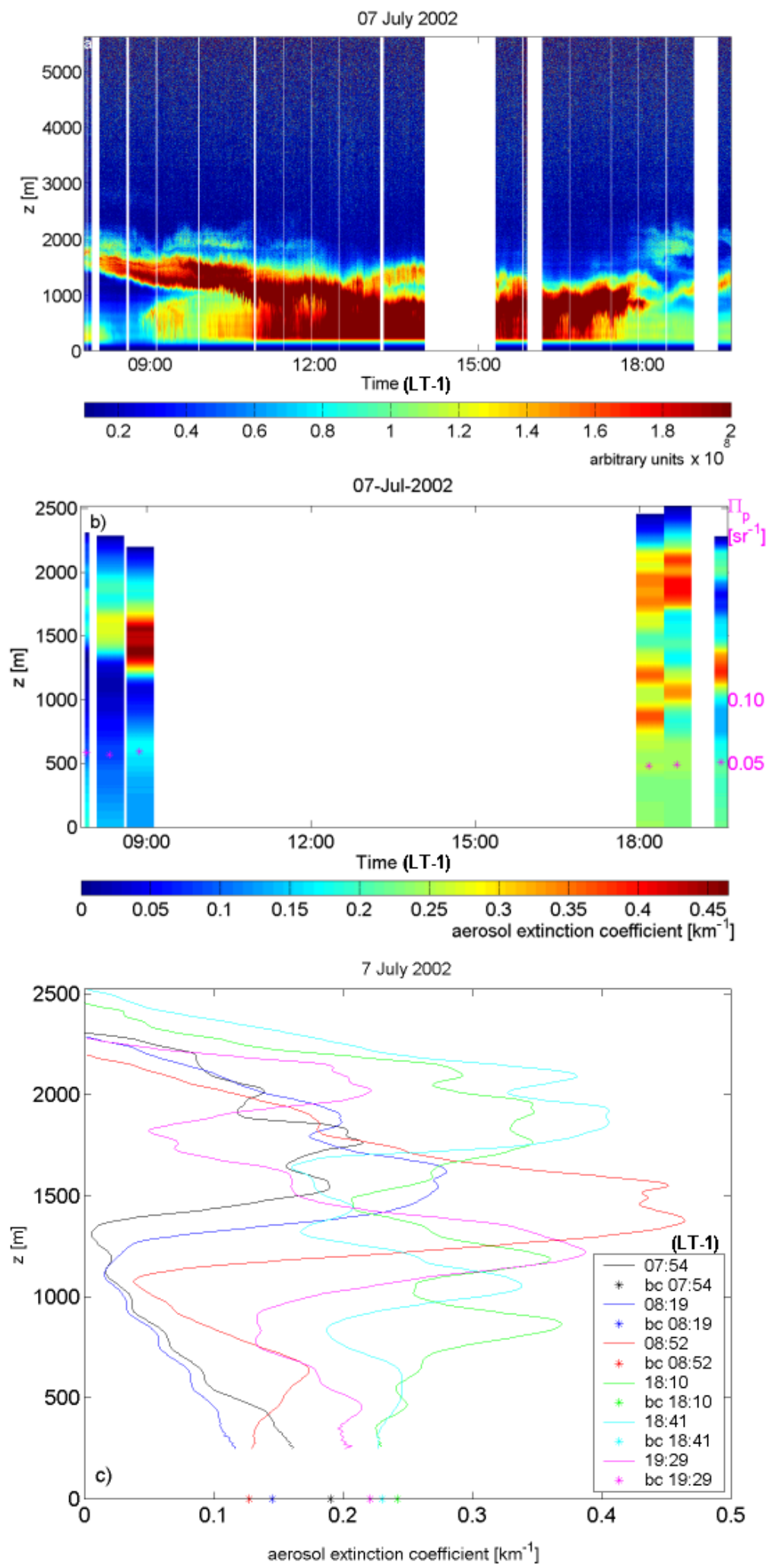

Figure 7. Same as Figure 6 for 7 July 2002.

coefficient profiles does not work for particularly high turbid atmosphere observed on 7 July. We presume that for this situation, multiple scattering cannot be ignored. The maxima in the extinction profiles correspond to the smoke layer. The extinction values at ground level (marked by asterisks in Figure 7c) were large $\left(0.13-0.24 \mathrm{~km}^{-1}\right)$, whereas those in the region of smoke layers were higher with a maximum of $0.45 \mathrm{~km}^{-1}$ at $1000 \mathrm{LT}$ around $1.5 \mathrm{~km}$. 

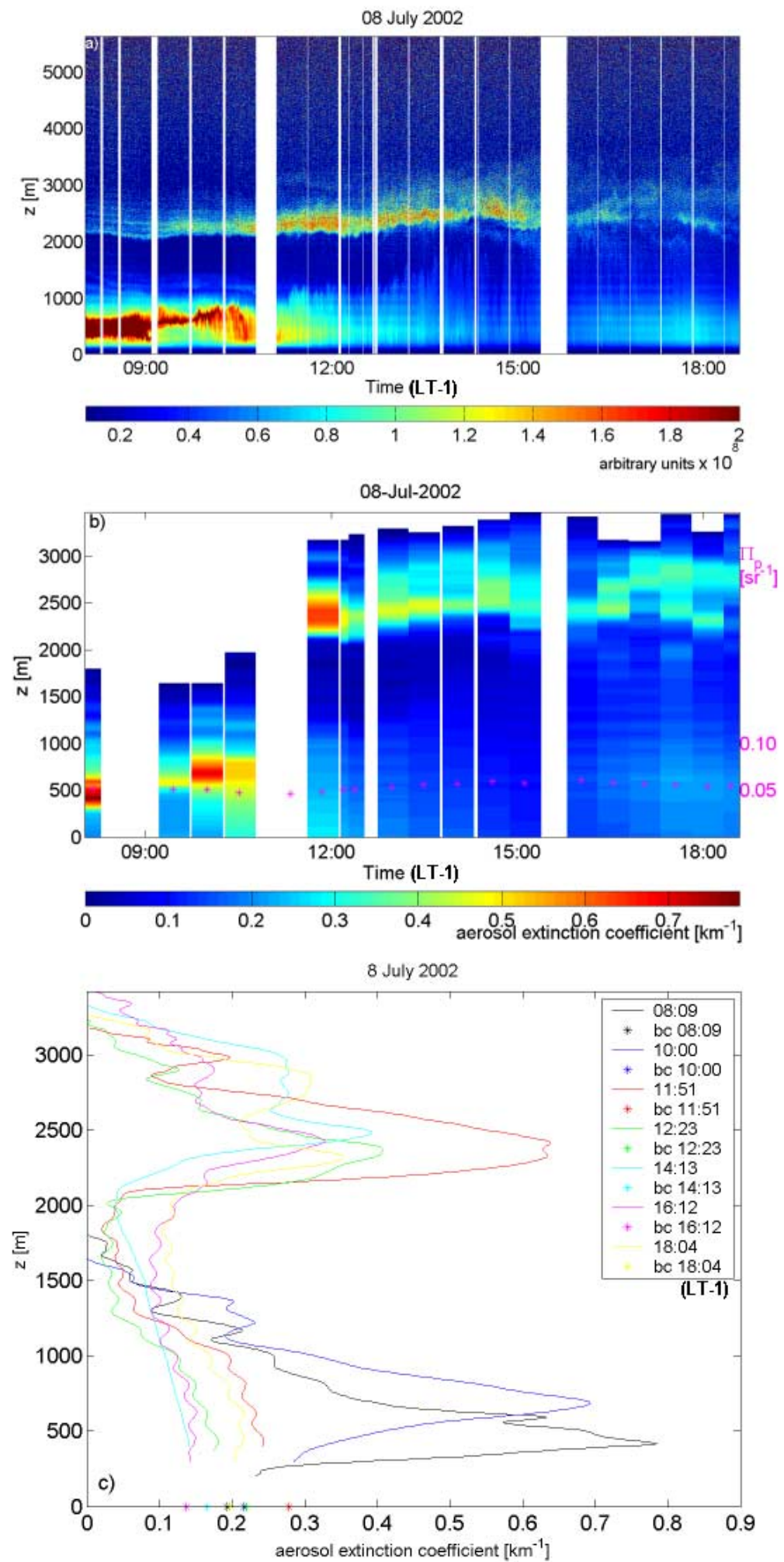

Figure 8. Same as Figure 6 for 8 July 2002.

Higher values are expected during the mixing of the smoke layer with the ABL (1100-1900 LT). For 8 July (Figure 8) the aerosol extinction is still high, especially in the aerosol layer and in the region of a plume arising from the ground during the first part of the day (from 0900 to
1200 LT). At ground level the values were still high, ranging from 0.12 to $0.34 \mathrm{~km}^{-1}$, whereas in the region of the plume intrusion and of the smoke layer the values are larger (maximum $0.7 \mathrm{~km}^{-1}$ around $0900,400 \mathrm{~m}$ ). On 9 July (Figure 9), slightly cloud cover was predominant 

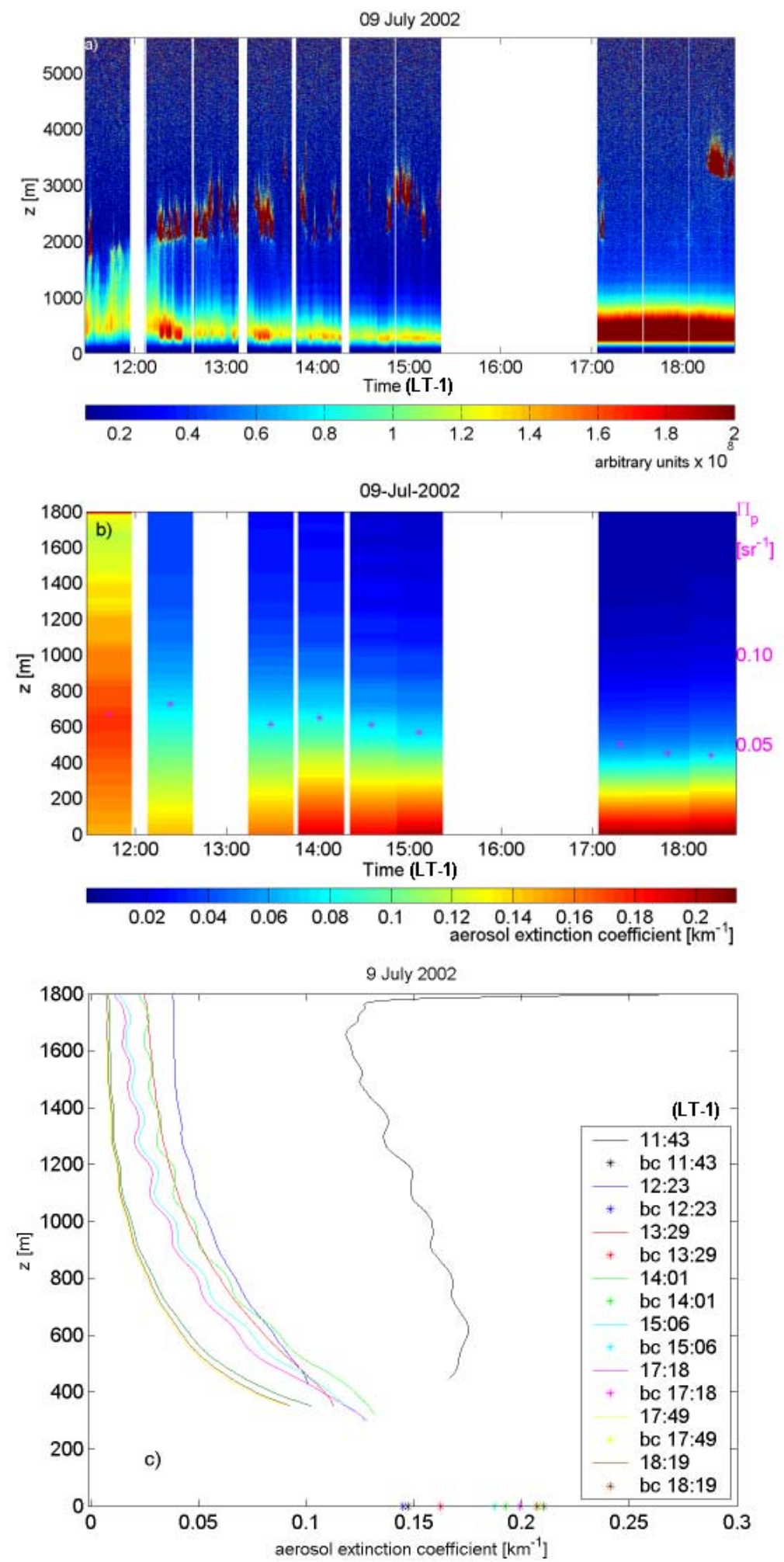

Figure 9. Same as Figure 6 for 9 July 2002.

$(\sim 2-3 \mathrm{~km}$, as indicated in Figure 9a). The plots of the extinction profiles are shown in Figure 9b, where only the first $1800 \mathrm{~m}$ are displayed to emphasize the ABL. The extinction coefficient is lower than in previous days, but it can be considered still large (with a maximum around
$0.21 \mathrm{~km}^{-1}$ ). Figure $9 \mathrm{c}$ displays the few vertical profiles at different time stamps also in the range up to $1800 \mathrm{~m}$. It should be mentioned that the presence of a cloud layer at the far end of the measurement range does not have an impact on the aerosol extinction coefficient retrieval below 

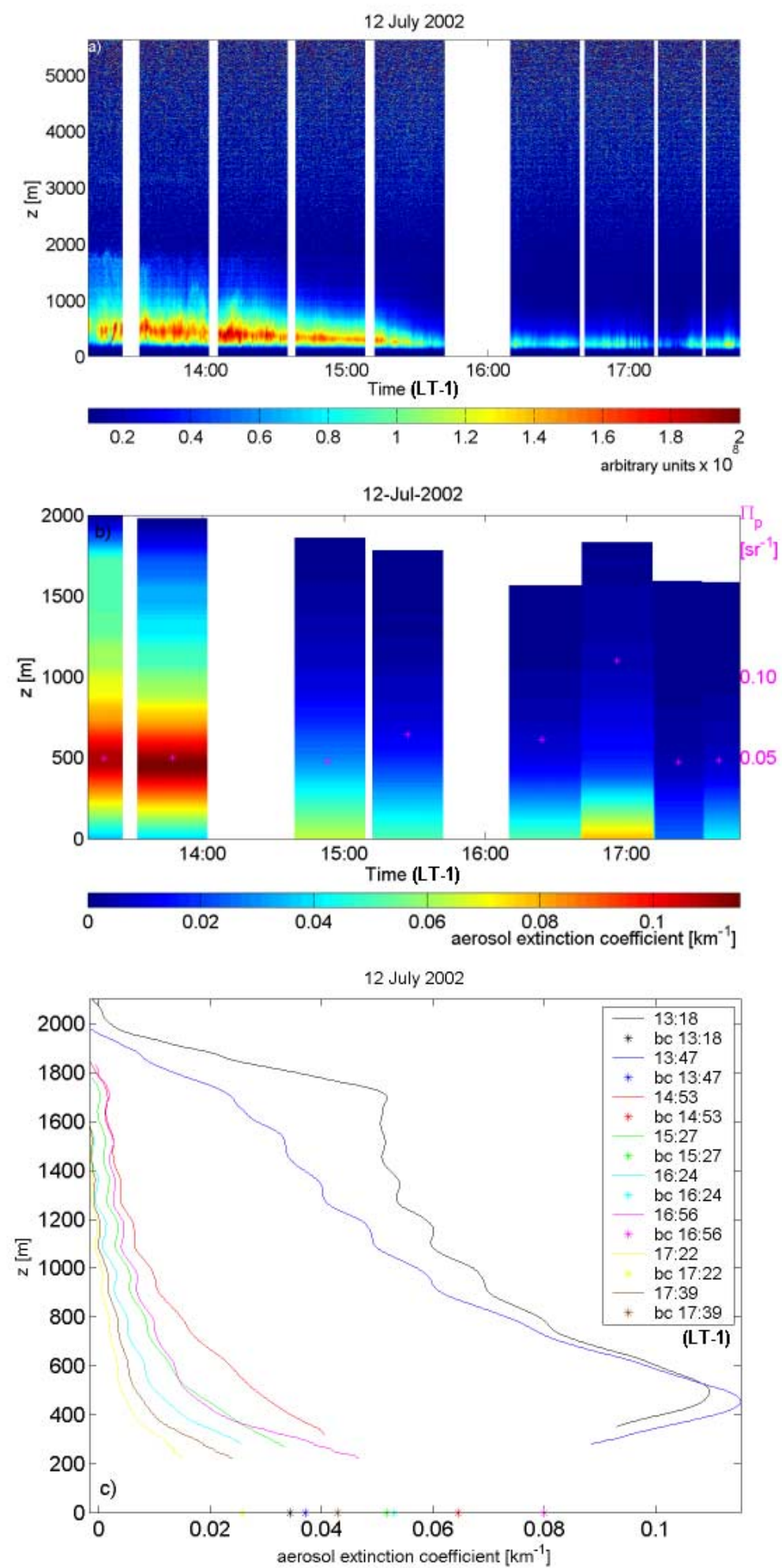

Figure 10. Same as Figure 6 for 12 July 2002.

the cloud since we use a near-end solution approach. However, the retrieval may be less accurate within the cloud layer due to possible MS within the cloud and a sharp change in LR on the cloud boundary. Hence we chose to plot the aerosol extinction profiles beneath clouds only. The 12th of July (Figure 10) was a clear day, characterized by small aerosol extinction coefficients (smaller than $0.12 \mathrm{~km}^{-1}$ ). The profiles and temporal variation of the extinction coefficient are shown in the Figures $10 \mathrm{~b}$ and $10 \mathrm{c}$. Relatively large values can be seen 
during the plume present in first part of the period $(\sim 1400-1600$ LT).

\section{Summary}

[35] Aerosol optical properties were investigated at the Baltimore PM Supersite experiment in east Baltimore, and a modified OAM method was used to invert the lidar equation. The method incorporates additional measurements to compute the lidar ratio and the boundary condition at ground level. Nevertheless, this remains an ill-posed problem since one might obtain several refractive indices that match the scattering profile. The value found for the refractive index $(m=1.5-0.47 i)$ is consistent with ambient air that is strongly influenced by heavy traffic. In comparison, Dalzell and Sarofim [1969], using the Kramers-Krönig dispersion formula, obtained refractive indices of $1.59+$ 0.58 and $1.63+0.70 i$ for 0.532 and $1.064 \mu \mathrm{m}$, respectively. LaRocca and Turner [1975] report refractive indices of $1.83+0.74$ and $1.95+0.68 i$ for the same wavelengths, while Müller et al. [2001] estimated a value for soot like particles of 1.75-0.45i for both wavelengths. Smyth and Shaddix [1996] provide a detailed discussion about the refractive index of soot. The scattering coefficients calculated using the three refractive indices above are well correlated with the measured scattering in each case $(\sim 0.98)$. However, the computed extinction coefficient boundary value at $1.064 \mu \mathrm{m}$ differs from those obtained with our estimated refractive index. Comparisons were made for three extinction profiles using ground boundary conditions of $0.0429,0.1075$, and $0.2072 \mathrm{~km}^{-1}$. For instance, using the refractive index $1.63-0.7 i$ at $1.064 \mu \mathrm{m}$ resulted in boundary conditions which differed by about $17 \%$ in each case. The AOD of the new profiles differed by about $20 \%$ from the AOD of our profiles. The second refractive index $(1.85-0.68 i)$ gave similar results, while the third refractive index $(1.75-0.45 i)$ gave a somewhat closer $(\sim 7 \%)$ match of the extinction coefficient profiles with the ones we determined and a difference in the AOD about $9 \%$.

[36] Future work will include the development of a dispersion relation between 0.530 and $1.064 \mu \mathrm{m}$. Incorporating the chemical composition will improve the analysis, as the range of refractive indices can be restricted. A direct calculation of the refractive index (as well as of the mean density) will follow from the species analysis (using the volume-weighted method). For example, see the papers by Ouimette and Flagan [1982] and Hasan and Dzubay [1983]. The indirect method to estimate the refractive index using Mie theory will also be compared with the direct method using species analysis. The derived mass concentration will be compared with the measured TEOM PM2.5. Finally, the density inferred to compute the derived mass will be compared with the density given by the species analysis.

[37] In this paper the lidar ratio has been assumed to be constant with height. No other supporting measurements within the boundary layer were available. As a result of real changes in aerosol properties with height (size distribution, chemical composition, and humidity), the lidar ratio estimates are inaccurate and thus prohibit a proper estimation of the vertical extinction profile and the aerosol optical depth. As we mentioned earlier, using a constant lidar ratio over the vertical range will result in errors in extinction coefficient in and above the ABL, but they are not particularly high for $1.064 \mu \mathrm{m}$, as we discussed earlier.

[38] The measured aerosol scattering from the nephelometer at $0.530 \mu \mathrm{m}$ ranged from $\sigma_{p}=0.002$ to $\sigma_{p}=0.541 \mathrm{~km}^{-1}$, whereas the computed aerosol extinction coefficient with Mie theory at $0.530 \mu \mathrm{m}$ ranged from $\kappa_{p}=0.010$ to $\kappa_{p}=$ $1.05 \mathrm{~km}^{-1}$. In the present study the aerosol optical properties were dominated by light absorption. The single scattering albedo, determined using the computed scattering and extinction (at $\lambda=0.530 \mu \mathrm{m}$ ), was found to be $0.3581 \pm$ 0.0625 , with minimum and maximum values of 0.1791 and 0.5106 , respectively. The small values of the albedo are directly related to strong absorption by the soot. Future studies should include a direct measurement of the aerosol absorption coefficient.

[39] A good correlation was found between derived mass and measured aerosol scattering coefficient $(R=0.91)$. The derived mass ranged between 4 and $194 \mu \mathrm{g} \mathrm{m}^{-3}$. The maximum was reached on 7 July at 1330 LT, which agreed favorably with the TEOM PM2.5 which measured a mean value of 197.94 between 1330 and 1400 LT. The mass scattering coefficient (or mass scattering efficiency) ranged between 0.2 and $3.3 \mathrm{~m}^{2} \mathrm{~g}^{-1}$.

[40] The extensive monitoring with both in situ and remote sensing instruments during the Baltimore PM Supersite experiment provided valuable data on aerosol optical properties. Other work, related to the Baltimore PM Supersite, will build upon these results and assess the influence air pollution exerts on human health in this environment [e.g., Adam et al., 2004].

[41] Acknowledgments. The authors wish to thank Jan Kleissl, Elie Bou-Zeid, Vijayant Kumar, and Chad Higgins from the Johns Hopkins University for their assistance in the field and David Harrison for helpful information with regard to SMPS and APS data. We gratefully acknowledge the loan of equipment by Phil Hopke (Clarkson University) and the detailed comments provided by the three anonymous reviewers. This research has been supported by the U.S. Environmental Agency (EPA 99-NCERQA_X1).

\section{References}

Ackermann, J., P. Völger, and M. Wiegner (1999), Significance of multiple scattering from tropospheric aerosols for ground-based backscatter, Appl. Opt., 38(24), 5195-5201.

Adam, M., J. M. Ondov, and M. B. Parlange (2004), Determination of aerosol extinction coefficient profiles from elastic backscatter lidar at $1064 \mathrm{~nm}$ using the near-end solution: Uncertainties arising from estimation of the boundary conditions, in Proceedings of XXIIth International Laser Radar Conference, ESA Spec. Publ. SP-561, Eur. Space Ag., Paris, in press.

Althausen, D., D. Müller, A. Ansmann, U. Wandinger, H. Hube, E. Clauder, and S. Zörner (2000), Scanning 6-wavelength 11-channel aerosol lidar, J. Atmos. Oceanic Technol., 17, 1469-1482.

Barnaba, F., and G. P. Gobbi (2001), Lidar estimation of tropospheric aerosol extinction, surface area and volume: Maritime and desert-dust cases, J. Geophys. Res., 106(D3), 3005-3018.

Bohren, C. F., and D. R. Huffman (1983), Absorption and Scattering of Light by Small Particles, John Wiley, Hoboken, N. J.

Carrico, C. M., M. H. Bergin, J. Xu, K. Baumann, and H. Maring (2003), Urban aerosol radiative properties: Measurements during the 1999 Atlanta Supersite Experiment, J. Geophys. Res., 108(D7), 8422, doi:10.1029/ 2001JD001222.

Charlson, R. J. (1969), Atmospheric visibility related to aerosol mass concentration, Environ. Sci. Technol., 3(10), 913-918.

Charlson, R. J., S. E. Schwartz, J. M. Hales, R. D. Cess, J. A. Coakley, J. E. Hansen, and D. J. Hofmann (1992), Aerosols and global warming response, Science, 256(5057), 598-599.

Collis, R. T. H. (1966), Lidar: A new atmospheric probe, Q. J. R. Meteorol. Soc., 92, 220-230. 
Collis, R. T. H., and P. B. Russell (1976), Lidar measurement of particles and gases by elastic backscattering and differential absorption, in Laser Monitoring of the Atmosphere, edited by E. D. Hinkley, pp. 71-152, Springler-Verlag, New York.

Dalzell, W. H., and A. F. Sarofim (1969), Optical constants of soot and their application to heat-flux calculations, Heat Transfer, J., 91, 100-104

Dubovik, O., B. Holben, T. F. Eck, A. Smirnov, Y. J. Kaufman, M. D. King, D. Tanre, and I. Slutsker (2002), Variability of absorption and optical properties of key aerosol types observed in worldwide locations, J. Atmos. Sci., 59(3), 590-608.

Edlen, K. (1966), The refractive index of air, Metrologia, 2(2), 71-80.

Elterman, L. (1970), Vertical attenuation model with eight surface meteorological ranges 2 to 13 kilometers, Rep. AFCRL-70-0200, U.S. Air Force, Washington, D. C.

Fernald, F. G. (1984), Analysis of atmospheric lidar observations: Some comments, Appl. Opt., 23(5), 652-653.

Ferrare, R. A., S. H. Melfi, D. N. Whiteman, K. D. Evans, and R. Leifer (1998a), Raman lidar measurements of aerosol extinction and backscattering: 1. Methods and comparisons, J. Geophys. Res., 103(D16), $19,663-19,672$

Ferrare, R. A., S. H. Melfi, D. N. Whiteman, K. D. Evans, M. Poellot, and Y. J. Kaufman (1998b), Raman lidar measurements of aerosol extinction and backscattering: 2. Derivations of aerosol real refractive index, singlescattering albedo, and humidification factor using Raman lidar and aircraft size distribution measurements, J. Geophys. Res., 103(D16), $19,673-19,689$.

Flamant, C., et al. (2000), Airborne lidar measurements of aerosol spatial distribution and optical properties over the Atlantic Ocean during a European pollution outbreak of ACE-2, Tellus, Ser. B, 52, $662-677$.

Gobbi, G. P., F. Barnaba, M. Blumthaler, G. Labow, and J. R. Herman (2002), Observed effects of particles nonsphericity on the retrieval of marine and desert dust aerosol optical depth by lidar, Atmos. Res., 61, $1-14$

Gobbi, G. P., F. Barnaba, R. van Dingenen, J. P. Putaud, M. Mircea, and M. C Facchini (2003), Lidar and in situ observations of continental and Saharan aerosol: Closure analysis of particles optical and physical properties, Atmos. Chem. Phys. Discuss., 3, 445-477.

Hasan, H., and T. G. Dzubay (1983), Apportioning light extinction coefficients to chemical species in atmospheric aerosol, Atmos. Environ., 17(8), $1573-1581$

Hobbs, P. V. (1993), Aerosol-cloud interactions, in Aerosol-Cloud-Climate Interactions, edited by P. V. Hobbs, pp. 33-69, Academic, San Diego, Calif.

Hoff, R. M., H. A. Wiebe, and L. Guise-Bagley (1996), Lidar, nephelometer, and in situ aerosol experiments in southern Ontario, J. Geophys. Res., 101(D14), 19,199-19,209.

Horvath, H. (1998), Influence of atmospheric aerosols upon the global radiation balance, in Atmospheric Particles, edited by R. M. Harrison and R. van Grieken, pp. 543-596, John Wiley, Hoboken, N. J.

Houghton, J. T., , Y. Ding, D. J. Griggs, M. Noguer, P. J. van der Linden, X. Dai, K. Maskell, and C. A. Johnson (Eds.) (2001), Climate Change 2001: The Scientific Basis: Contribution of Working Group I to the Third Assessment Report of the Intergovernmental Panel on Climate Change, Cambridge Univ. Press, New York.

Hulbert, E. O. (1941), Optics of atmospheric haze, J. Opt. Soc. Am., 31(7), $467-476$.

Klett, J. D. (1985), Lidar inversion with variable backscatter/extinction ratios, Appl. Opt., 24(11), 1638-1643.

Kovalev, V. A. (1995), Sensitivity of the lidar solution to errors of the aerosol backscatter-to-extinction ratio: Influence of a monotonic change in the aerosol extinction coefficient, Appl. Opt., 34(18), 3457-3462.

Kovalev, V. A. (2003), Stable near-end solution of the lidar equation for clear atmosphere, Appl. Opt., 42(3), 585-591.

Kovalev, V. A., and H. Moosmüller (1994), Distortion of particulate extinction profiles measured with lidar in a two-component atmosphere, Appl. Opt., 33(27), 6499-6507.

LaRocca, A. J., and R. E. Turner (1975), Atmospheric transmittance and radiance: Methods of calculation, Rep. 107600-10-T, Environ. Res. Inst. of Mich., Ann Arbor.
Marenco, F., V. Santacesaria, A. F. Bais, D. Balis, A. di Sarra, A. Papayannis, and C. Zerefos (1997), Optical properties of tropospheric aerosols determined by lidar and spectrophotometric measurements (Photochemical Activity and Solar Ultraviolet Radiation Campaign), Appl. Opt., 36(27), 6875-6886.

Mayor, S. D., and E. W. Eloranta (2001), Two-dimensional vector wind fields from volume imaging lidar data, J. Appl. Meteorol., 40, 1331-1346.

Mishchenko, M. I. (2000), Calculation of the amplitude matrix for a nonspherical particle in a fixed orientation, Appl. Opt., 39(6), 1026-1031.

Mishchenko, M. I., L. D. Travis, and A. Macke (2000), T-matrix method and its applications, in Light Scattering by Nonspherical Particles, edited by M. I. Mishcenko, J. W. Hovenier, and L. D. Travis, pp. 147-172, Academic, San Diego, Calif.

Müller, D., U. Wandinger, D. Althausen, and M. Fiebig (2001), Comprehensive particle characterization from three-wavelength Raman-lidar observations: Case study, Appl. Opt., 40(27), 4863-4869.

NASA (1976), U.S. Standard Atmosphere Supplements, 1976, U.S. Govt. Print. Off., Washington, D. C

Ouimette, J. R., and R. C. Flagan (1982), The extinction coefficient of multicomponent aerosols, Atmos. Environ., 16(10), 2405-2419.

Pahlow, M., J. Kleissl, M. B. Parlange, J. Ondov, and D. Harrison (2004a), Atmospheric boundary layer structure as observed during a haze event due to forest fire smoke, Boundary Layer Meteorol., in press.

Pahlow, M., V. A. Kovalev, and M. B. Parlange (2004b), Calibration method for multiangle lidar measurements, Appl. Opt., 43(14), 2948-2956.

Redemann, J., R. P. Turco, R. F. Pueschel, E. V. Browell, and W. B. Grant (1996), Comparison of aerosol measurements by lidar and in situ methods in the Pacific basin troposphere, in Advances in Atmospheric Remote Sensing With Lidar: Selected Papers of the 18th ILRC, edited by A. Ansmann et al., pp. 55-58, Springer-Verlag, New York.

Redemann, J., et al. (2000), Retrieving the vertical structure of the effective aerosol complex index of refraction from a combination of aerosol in situ and remote sensing measurements during TARFOX, J. Geophys. Res., 105(D8), 9949-9970.

Sasano, Y., and E. V. Browell (1989), Light scattering characteristics of various aerosol types derived from multiple wavelength lidar observations, Appl. Opt., 28(9), 1670-1679.

Sassen, K., and B. S. Cho (1992), Subvisual-thin cirrus lidar dataset for satellite verification and climatological research, J. Appl. Meteorol., 31, $1275-1285$.

Sassen, K., M. K. Griffin, and G. C. Dodd (1989), Optical scattering and microphysical properties of subvisual cirrus clouds, and climatic implications, J. Appl. Meteorol., 28, 91-98.

Sloane, C. S. (1986), Effect of composition on aerosol light scattering efficiencies, Atmos. Environ., 20(5), 1025-1037.

Smyth, K. C., and C. R. Shaddix (1996), The elusive history of $\mathrm{m}=1.57-$ $0.56 \mathrm{i}$ for the refractive index of soot, Combust. Flame, 107, 314-320.

Upendra, N. S., S. Ismail, and G. K. Schwemmer (Eds.) (1998), Nineteenth International Laser Radar Conference, Rep. NASA/CP-1998-207671/ PT2, NASA, Greenbelt, Md.

van de Hulst, H. C. (1981), Light Scattering by Small Particles, Dover, Mineola, N. Y.

Weinman, J. (1988), Derivation of atmospheric extinction profiles and wind speed over the ocean from a satellite-borne lidar, Appl. Opt., 27(19), 3994-4001

Welton, E. J., K. J. Voss, P. K. Quinn, P. Flatau, K. Markowicz, J. Campbell, J. D. Spinhirne, H. R. Gordon, and J. Johnson (2002), Measurements of aerosol vertical profiles and optical properties during INDOEX 1999 using micropulse lidars, J. Geophys. Res., 107(D1), 8019, doi:10.1029/ 2000JD000038.

M. Adam, M. Pahlow, and M. B. Parlange, Department of Geography and Environmental Engineering, Johns Hopkins University, 3400 N Charles St., 319 Ames Hall, Baltimore, MD 21218, USA. (mariana@jhu.edu) V. A. Kovalev, Fire Science Laboratory, U.S. Department of Agriculture, Missoula, MT 59807, USA.

N. Nair and J. M. Ondov, Department of Chemistry and Biochemistry, University of Maryland, College Park, MD 20742, USA. 